\title{
The Voluntary Partnership Agreement: the Ghanaian and Malaysian experience
}

\begin{abstract}
This paper looks at how the Voluntary Partnership Agreement is working by using the Ghanaian and Malaysian experiences on this process. The difference in the forest management system in both Ghana and Malaysia, in itself poses some challenges to the implementation of the VPA. Further, the multi-stake holder approach used in Ghana, and the inter-governmental approach used in Malaysia presents different scenarios that may influence the implementation of the VPA. It is important to realize that measures that properly address circumvention and illegal imports from non-partner countries are of crucial importance for Voluntary Partnership Agreements (VPAs) to be a success. Therefore, the only way for Ghana and Malaysia to see VPA as a success is to be assisted in every way to build capacity among the law enforcement agencies.
\end{abstract}

Keyword: FLEGT, Ghana, Governance, Malaysia, VPA 